\title{
Using Visual Representations as Boundary Objects to Resolve Conflict in Collaborative Model-Building Approaches
}

\section{Authors: Laura J. Black and David F. Andersen}

This is the peer reviewed version of the following article: [Black, Laura J., and David F. Andersen. "Using Visual Representations as Boundary Objects to Resolve Conflict in Collaborative Model-Building Approaches." Systems Research and Behavioral Science 29, no. 2 (March 2012): 194-208. doi:10.1002/sres.2106.], which has been published in final form at http://dx.doi.org/10.1002/sres.2106. This article may be used for non-commercial purposes in accordance with Wiley Terms and Conditions for Self-Archiving.

Black, Laura J., and David F. Andersen. "Using Visual Representations as Boundary Objects to Resolve Conflict in Collaborative Model-Building Approaches." Systems Research and Behavioral Science 29, no. 2 (March 2012): 194-208. doi: 10.1002/sres.2106.

Made available through Montana State University's ScholarWorks scholarworks.montana.edu 


\title{
Using Visual Representations as Boundary Objects to Resolve Conflict in Collaborative Model-Building Approaches
}

\author{
Laura J. Black $^{1 *}$ and David F. Andersen ${ }^{2}$ \\ ${ }^{1}$ Montana State University, College of Business, PO Box 173040, Bozeman, MT, USA \\ ${ }^{2}$ Rockefeller College of Public Affairs and Policy, University at Albany-State University of New York, Albany, \\ NY, USA
}

In the context of facilitated, technology-supported efforts to resolve complex problems, we recognize the critical role that visual representations can play in both the content and process of collaboration. How these representations are wielded by facilitators and interpreted by participants determines whether they help resolve conflicts or close down conversations. We identify three key attributes of scripted problem-solving facilitation, as well as three key attributes of visual representations that function as boundary objects, to gain insights into pivotal experiences when group problem-solving efforts turned from collaboration to conflict and vice versa. We draw on three vignettes from facilitated group problem solving to illustrate how these attributes can be deployed to move conflict-mired conversations into collaborative discussions. This paper contributes to collaborative problem solving by using the formal sociological theory of boundary objects to offer a deeper, richer understanding of successes and shortcomings of visual representations as drivers of conflict resolution in model-building approaches. Copyright (c) 2012 John Wiley \& Sons, Ltd.

\section{INTRODUCTION}

Group model building is an effective approach to collaborative problem solving (Vennix, 1996; Vennix et al., 1996; Andersen and Richardson,
1997; Andersen et al., 1997; Vennix, 1999). It interactively involves stakeholders in problem identification and problem-solving processes using the methods of system dynamics modelling (Randers, 1980; Wolstenholme, 1994), from behavior-overtime graphs through model conceptualization and simulation analyses. The approach is particularly desirable when addressing 'messy problems' (Ackoff, 1979; Vennix et al., 1996; Vennix, 1999) 
or 'wicked problems' (Rittel and Webber, 1973), when participants' resources and objectives may depend on or constrain other participants' resources, actions and objectives. Vennix (1996) has advocated that group model building can help people, quite literally, 'get on the same page' in understanding the common ground and opportunities among them, and Andersen and Richardson (1997) have reported that the process has generated collective insights about why problems persist despite organizations' best efforts to address them decisively.

Group model-building sessions rely on a facilitator (Richardson and Andersen, 1995) to move participants through a structured process of problem articulation and problem-solving explorations. The process includes both low-tech, high-touch aspects, such as capturing participants' contributions on flip charts or a white board or other large, visible writing space, and technologically based representations that synthesize participants' input in sketches, maps and simulating models.

This paper focuses particularly on how visual representations, both low-tech and high-tech, function in group model-building collaborative efforts. We assert that when visual representations function as 'boundary objects' they turn situations of disagreement, tension and conflict into collaborative problem-solving discussions. A construct from sociology, a boundary object (Star and Griesemer, 1989; Henderson, 1991) is a tangible representation of dependencies across disciplinary, organizational, social or cultural lines that all participants can modify. It can effectively advance shared understanding when participants can transform the representation to show more clearly their understanding of the dependencies among them and the implications for each participant's resources, operations and goals (Carlile, 2002).

In the following, we describe three collaborative problem-solving efforts in which the groups were struggling with conflict of one sort or another. Two of the vignettes have been selected from our own repertoire of facilitation and modelling experiences and one is from the direct experience of a close professional colleague; each illustrates particular instances of visual representations as part of facilitated model-building efforts. In the section following the vignettes, we examine the theory and practices of structured, planned activities of facilitation and underscore how conflict and unintended results can emerge from scripted behaviors. Next, we summarize the theory of boundary objects and explain generally the conditions under which visual representations can serve as boundary objects or, alternatively, as conscripting or bludgeoning tools. We examine the role that visual representations played in each of the three vignettes in light of these principles and interpret the planned and unplanned dynamics emerging in each situation according to how visual representations were used. Finally, we present an analytic discussion that presents in summary form a vision of why and how boundary objects can support reaching agreement by conflictive groups and offer concluding thoughts.

\section{METHODS USED IN THIS PAPER}

This study emerged from a combination of action research (Schein, 1969; Argyris, 1993; Eden and Huxham, 2006) and case study review (Eisenhardt, 1989). Collectively, the authors of this paper have extensive experience working with facilitated groups, with many of those years involving computer-assisted face-to-face group modelling sessions. We each associated with several sets of long-term and experienced modeller-facilitator pairings, with these pairings having cumulative decades of experience in this kind of work. Although most of our efforts have been with collaborating groups, an important minority of our work has of necessity involved groups experiencing conflict of one form or another. Indeed, some of our most vivid experiences-opportunities to learn and grow in modelling and facilitation practices-arise from conflictive groups. Both authors also have significant experience conducting research on group model building and facilitated projects, motivated by a belief that systematic reflection on and study of group processes can lead to improvement in these practices for ourselves and others. 
THREE SCENARIOS OF CONFLICTS AND COLLABORATIONS

\section{Vignette \#1: Strategies for Public Security in a Region of Ethnic Violence}

Colleagues of ours were working with senior public security offices in a region that had recently experienced increased ethnic violence and terrorism. Ethnic violence had been a long-standing part of the region's history. This modelling and strategy development conference was attended by senior officers of the police and security forces who shared interests in keeping all the public safe, preventing bomb explosions in public places and eliminating assassinations. But the ethnic groups that these police and security forces represented had a history of suspicion and mutual recriminations, if not outright hate. Cooperating with or even agreeing with people perceived as 'the other side' risked being seen as small acts of ethnic treason.

An early activity of this strategy mapping and modelling session was the creation of an issue map. The group task was simple - a script asking individuals to write down one issue surrounding public safety in the region and then paste it on a public space. They were to do this exercise over and over until all relevant issues were visible for everyone in the group to review and discuss. This activity is usually a fast way to surface and share a robust mixture of problems, goals, assumptions and even hints for solutions. Later, these issue maps could be sorted into agreedupon statements of common goals linked to action steps and assumptions that would support a map of common goals.

The special problem for this particular session stemmed from the long history of conflict among members of the group. It was implicitly the case that, 'If they asserted or proposed something, then we will have to oppose it.' On that day, therefore, facilitators arranged for the issue map to be constructed using Group Explorer, a networked version of the Decision Explorer software. The room was equipped with a network of about a dozen personal computers with pairs or small groups of security officers (from the same ethnic group) working at each machine. When they entered an issue at their keyboard, it appeared on a common projected screen. Whereas the group facilitator and modeller could identify who had said what, participants could not. Issues and ideas were detached from their authors and could be taken (or rejected) only on their own merit.

After the initial brainstorming of issues, two or more ideas could be clustered to craft a new thought. Members of the group could argue over a particular idea or over a linkage between two or more issues without knowing to whom the original ideas and links belonged. Security officers could amend issue statements and craft new views, all the while being ignorant of the ethnic origins of the original ideas. This group eventually crafted a common statement of security goals for the region and agreed upon a set of policy actions, tied to key strategic assumptions and resource requirements to support the proposed policy actions.

\section{Vignette \#2: Conflicting Views of Pricing Policies in a Commodity Market}

A member of the authoring team was engaged in a system dynamics group model-building effort with the executive team of a major multinational firm that operates capital-intensive plants in a commodity market. At the time of the modelling exercise, the market was experiencing a relative over-expansion of capital infrastructure worldwide, and profit margins for the industry were falling precipitously from pressures due to the trough of a commodity cycle. This corporation, a technology leader in its field, had in the past been able to differentiate its product from the mainstream commodity market, but capital plants around the world were increasingly able to replicate innovations, and traditional price premiums enjoyed by the client were eroding.

The system dynamics group modelling project was sponsored by a corporate vice president with responsibilities in areas of innovation and research and development, but the CEO of the firm was the 'meeting owner', and in addition to other executives, a number of senior operations managers responsible for global operations and sales were participants in the room. The group model-building 
session had begun with a concept model based on published simulations of commodity markets that was more elaborated than most initial concept models (see Richardson, 2006 and Scriptapedia; Hovmand et al., 2011 for a description of concept models). The next stage of the facilitated process involved the group's elaborating the model's initial feedback structure to accommodate particular details of the firm's pricing formation as it interacted with the industry as a whole. A particularly thorny issue centred on mapping how existing commodity market mechanisms interacted with industry-wide price-reporting groups and the sales policies of individual companies to create an informal, publicly visible and commonly agreed upon price marker for various well-defined segments of the commodity's international market.

Sales, operations and finance all had slightly different views of how the firm's internal price setting interacted with the industry's formal price reporting. There was disagreement within the senior management team over how these pricing interactions dynamically played out and what direction the firm should take in its internal pricing policies. The stakes were high because, in these over-capitalized markets, small differences in price margins could mean the difference between survival and having to close one or more production facilities.

The CEO, who had been following the vigorous discussion and arguments with interest, finally weighed in with his point of view. He had a forceful, hard-hitting, no-nonsense style of presentation, and he laid out what he believed the firm should do next in clear and compelling terms. His intervention seemed to settle the emergent conflict in the room. The facilitator called a break in the modelling process.

During the break, a member of the modelling and facilitation team took the CEO aside to review the morning and to comment on his dramatic intervention. The facilitator verbalized a tricky observation, 'Do you think that anyone in the room could disagree with you, given the way you just made your presentation?' The facilitator then asked him to re-start the meeting after the break, giving the group a sense of what direction he wanted to see.
After the break, the CEO opened the meeting and in less forceful terms re-stated his position about what action the firm should take. But he wanted to hear further debate and discussion. In the ensuing silence, the facilitator directed the group's attention to the pricing structure that they had been mapping in the model just before the break. The disagreements that had been in the room slowly re-emerged, but they were now focused on creating and discussing details of the map on the whiteboard. Individual words, phrases and causal arrows were all called into question and discussed.

During these detailed discussions, the facilitator kept the participants' focus on the emergent map on the white board rather than on the personalities voicing comments, and gradually, a new view of collective corporate strategy emerged. In the end, the view that emerged on the white board 'shouted down' in its own quiet way the CEO's position so vividly staked out before the break. He was pleased to have his initial thoughts replaced by a more empirically grounded, commonly supported and potentially more profitable idea. Future modelling efforts explored these collective ideas in more detail with wide/growing support among the executives and operations team.

\section{Vignette \#3: Inter-agency Social Policy Reform at the County Level}

Our third vignette has much in common with the second, but with a less fortunate conclusion. The client group was an inter-agency team of public sector managers from the United States assigned to work together on a county-wide set of cross-agency reforms in a specific area of social policy. The participants in the group model building consisted of managers from several county, state and municipal agencies as well as representatives of key non-governmental organizations who shared an interest in this particular policy area. The commissioner from one of the lead agencies was the meeting owner and had convened the entire group and given participants their charge to articulate a strategy for making cross-agency reforms.

As in the second vignette, facilitators began by presenting a basic concept model, quickly 
transitioning to causal mapping of system structure. At almost every step along this process, disagreement erupted between members of the strategy planning team. Individual members were articulating and adhering to the points of view of their own organizations, and most parts of the causal map emerged slowly from this vigorous discussion.

By noon of the second day, the scheduled adjournment for the meeting was within sight. Although progress had been made on many areas, the group had not reached consensus on several key points. It seemed clear to the facilitators that the session would reach its scheduled ending time with several of the meeting's key points still unsettled. During the noon break, facilitators consulted with the meeting owner. $\mathrm{Up}$ to this point, he had been actively engaged in both trying to build consensus while trying to advocate for his own agency's perspective.

After the break, the commissioner/meeting owner moved into a decisive leadership role. Because most of the disagreement had centred on details of the causal map being constructed by the group, he decided to sidestep these controversial images. Rather, he identified approximately eight key tasks that had emerged as candidate 'next steps' during the discussion that morning. In an effort to create momentum for the overall project, for each task, he identified a lead staff person, almost all from his own agency, and then assigned one or more of the other meeting members to the task. Sub-groups were expected to report on their progress at the next meeting.

The next meeting never happened. The crossagency teams assigned by the meeting owner to push forward on an assigned task simply did not take up the work. Attempts to re-schedule a next meeting failed. The social policy strategy for reform under discussion was never implemented.

SCRIPTED FACILITATED PROBLEM-SOLVING PROCESSES AND THEIR VISUAL 'PRODUCTS' AS POTENTIAL BOUNDARY OBJECTS

In this section, we examine previous work on facilitated problem solving using 'scripts' and research on visual representations as boundary objects.
Looking at the Vignettes' Scripted Processes for Technology-Supported Problem Solving

We identify three key attributes of facilitated technology-mediated problem solving:

- The process of the conversation and the content of the conversation are separated by design and by different individuals playing different roles (facilitators manage the process; participants manage the content).

- An implicit contract of trust between facilitators and participants exists.

- Explicit sub-processes-sometimes called scripts-focus clearly on creating products or deliverables that are visually shared and discussed.

Facilitated, technology-mediated problem solving requires the use of some technology (not necessarily sophisticated technologies) and a modicum of participants' trust in facilitators and in the processes and activities they propose. In each of the three vignettes described, the facilitation and modelling team was following a plan, a scripted plan of action for the session. These plans for sub-processes exist independent of the content the group wants to address. Almost all the scripted plans we know of presume that the client group is a collaborating team, or at least working on a shared problem or seeking to attain a shared goal. Scripted sub-processes also assume that the purpose of the facilitated modelling session is to create a consensus or agreement-an 'alignment of mental models' (Kim, 2009) as it were-through processes of exploring different perspectives on parts of a complex problem.

As evident in the aforementioned vignettes, however, scripted activities designed to help groups collaborate and create consensus can also prove useful in mitigating conflicts. We believe that the capacity to synthesize conflicting views and mitigate personal tensions relies largely on the boundary objects that are evoked and put into play in the facilitated modelling sessions. Before we describe what boundary objects are and why they can be useful both for creating consensus and for resolving conflict, we pause to examine literature on and approaches to scripted 
design of facilitated face-to-face group modelling sessions. This look at the published literature on scripted approaches to group model building offers some additional insights into what was going on in the three vignettes as well as into why two of the vignettes seem to have had relatively good outcomes whereas the third did not.

In the first vignette, the modelling team began by building an issue map. With the use of GroupExplorer (Ackermann and Eden, 2001), an issue map for nearly 100 concepts can be constructed by a group in less than $1 \mathrm{~h}$ (Ackermann et al., 2011). The detailed procedures for how to build these maps are described in Ackermann et al. (2005), which also provides a detailed process description, or script, for creating a goal map and an agreed-upon set of policy actions while working with a group. More recently, Ackermann et al. (2011) addressed a number of questions left open when one adopts a scripted approach to developing group model-building sessions. Should some scripts be performed first, whereas others wait until later? Are some scripts properly seen as prerequisites for others? In general, what guidance, if any, exists for practitioners who wish to assemble a series of scripts into a whole intervention plan that makes sense? 'ScriptsMap' (Ackermann et al., 2011) is a tool for addressing these questions, offering a network framework of sequences of scripted activities, products and deliverables to enable facilitators to construct appropriate combinations for workshops. The initial work laid out a map that combines scripts from traditional group model-building practices with Eden and Ackermann's (1998) approach to strategy development working directly with client groups. Eden et al. (2009) further elaborated on a number of practical and more theoretical dilemmas associated with attempts to integrate group modelling projects using diverse analytic methods.

In the second and third vignettes, the facilitation and modelling team was using scripts in much the same sequence as prescribed by the ScriptsMap (Ackermann et al., 2011). Both of these vignettes began with a 'graphs-over-time' script, designed to help a group identify a set of variables to include in the simulation model. The next script used was a 'concept model' script, designed to teach the basic vocabulary and iconography of system dynamics modelling in $25 \mathrm{~min}$ or less through a demonstration of the modelling using a simplified version of the presenting problem or objective. The group model-building sessions giving rise to the second and third vignettes were using a series of scripts designed to elicit group consensus on causes and interactions among causes of the problem when strong disagreements emerged. These scripts include a 'ratio script' and a script designed for 'elaborating model structure'. Finally, both meetings used a script for resolving conflict by facilitators talking with the meeting owner during a break. Of course, these two meetings ended with different outcomes, and the nature and effectiveness of participants' subsequent activities differed dramatically.

Each of the scripts has been more carefully described by Hovmand et al. (2011) in a catalogue of scripted behaviors called the 'Scriptapedia'. Each script begins with some 'products', or materials produced by earlier discussions, that are available at the beginning of the script and describes the group process used to transform these products into artefacts that represent the content of the group's discussion.

\section{Looking at Scripts' Visual 'Products' as Potential Boundary Objects}

Many of the products of group model-building processes are shared visual representations that portray participants' perspectives on the complex problem that brought them together. Visual images provide a significant input to the thinking process, and they can play a critical role in helping people re-conceptualize abstract problems (McKenzie and Winkelen, 2011). But the visual representations used in collaborative problem solving and group model building play an especially significant role in facilitating and shaping consensus when they function as boundary objects (LJ Black, 2011, working paper). Specifically, visual products of facilitated processes can serve as boundary objects when they have the following characteristics: 
- They are tangible two-dimensional or threedimensional shared representations (consider a diagram, sketch, prototype model, map, etc.- these representations can include text but, in our experience, the text is always sparse).

- They portray salient dependencies and relationships among participants' objectives, expertise, decisions and actions.

- Critically, they can be modified by input from every participant.

Here, we briefly describe the theoretical background related to boundary objects, which we then use to interpret how the visual representations functioned in each of the vignettes described in the preceding sections.

Lave's (1988) theory of distributed cognition asserted that cognition is not 'all in our minds' but distributed among our minds and bodies and the locations in which we exercise our competences. Although using visual representations in collaborating groups is not new, distributed cognition provides a strong theoretical basis for giving special focus to them in facilitated technology-supported problem-solving sessions. The visible 'products' of scripts provide tangible representations of how participants conceptualize the problem and therefore how solutions might be identified. In the group model-building setting, the representations customary to the system dynamics method offer opportunities to represent a familiar problem in ways that are different from 'just talking' about the problem. These visual representations especially focus on showing relationships among the problematic aspects that participants care about. If we take seriously the concept of distributed cognition, the emerging maps and models of a group model-building session offer content-rich, socially shared experiences that help participants recognize and change their individual and collective cognition, or how they think about the problem.

Shared visual representations do not facilitate collaboration, however, unless they function as boundary objects. Of course, boundaries can arise from differences in locations, organizational structures or entities, knowledge disciplines, expertise level or time frames for decision making because any of these gaps can create challenges in coordinating and collaborating on interdependent resources and activities. The term 'boundary object' was first coined by Star and Griesemer (1989), who defined it as an object 'adaptable' enough to be interpreted differently by people whose expertise differed without losing a coherent identity across the social worlds it is spanning. Star and Griesemer (1989) suggested that boundary objects are useful because they aid in negotiations when 'each social world has partial jurisdiction over the resources represented by th[e] object' (p. 412), but those jurisdictions overlap or are mismatched or in conflict.

Henderson (1991, 1998) elaborated on the notion of 'adaptable' objects, emphasizing the important role that many kinds of artefacts, tools and technologies play in the coordination of knowledge and competence, when one kind of expertise is insufficient to accomplish the task at hand. She studied the ways that drawings and sketches of products under development elicited voluntary innovative ideas or 'conscripted' participation in aspects of the products under development. Carlile (2002) also studied artefacts used to represent dependencies across functional boundaries in the context of product development and articulated three aspects characterizing a robust boundary object: representative of dependencies among the actors, relatively 'concrete', given the participants' differing expertise and experience and transformable by all actors. If an object is transformable, then anyone involved has the ability to manipulate and alter the representation to show more clearly the consequences of the dependencies she/he perceives.

\section{INTERPRETING THE VIGNETTES IN LIGHT OF SCRIPTS AND BOUNDARY OBJECTS}

Although neither boundary objects nor scripts have redistributing power as a primary objective, both boundary objects and scripts have significant implications for the use of power among participants during a collaborative problem-solving effort (Black, 2011, working paper). When visual representations function as boundary objects, they de-personalize issues in a way that spoken words do not and focus the conversation on dependencies and their consequences for participants' objectives 
and operational choices. The design of technologysupported facilitated problem-solving activities described in the previous section is premised on collaborative use of visual representations that successively build on (and sometimes challenge) previous agreements by participants. As mentioned in the previous section, facilitation and technology use enable a temporary rebalancing of power among participants as they relinquish to facilitators responsibility for managing the process and for making productive use of the content generated by participants. How the group problem-solving session unfolds, however, affects whether trust in technology-supported process and in facilitators managing the process grows or diminishes. If we use the lens of boundary objects to examine how the sessions unfolded in each of the aforementioned vignettes, we gain useful insights about the role that visual representations can play in the dynamics of collaboration.

Vignette \#1 Re-interpreted: Strategies for Public Security in a Region of Ethnic Violence

Conflict was part of the context at the outset of the group process in the first vignette. Conflict lay in the individual and community histories of participants, and violent conflict gave rise to a shared goal for public safety, the purpose in meeting. When participants were first asked to create an issue map by generating ideas and portraying them on a shared space, what in other settings can be a companionable brainstorming session here raised threats to participants' identities and loyalties. Their conflicts prevented them from building on one another's ideas because each idea was observed to be associated with the person who shared it. Notably, collaborative model building seldom employs anonymity because its goal is to increase participants' capacity to talk to one another productively about how to use their mutually dependent resources and actions to achieve their individual and shared objectives; masking the identity of participants' comments customarily undermines that goal. But in the public safety conversation, by altering the group process to use the GroupExplorer method (Ackermann and Eden, 2001) in which participants' comments were portrayed anonymously, the facilitators created a de-personalized, shared representation that permitted participants to suspend suspicions and begin to think together. The tool allowed participants to transform the shared representation of individual comments and build on one another's issues and ideas. It therefore functioned as a boundary object because it facilitated participants' transforming a shared representation, which helped them navigate in less threatening and risky ways to a shared understanding of what they could individually and collectively do to improve public safety.

\section{Vignette \#2 Re-interpreted: Conflicting View of Pricing Policies in a Commodity Market}

In the case of the multinational commodityproducing firm, participants shared a goal to agree on a pricing strategy that would help the firm survive the current price pressures in the industry. Interpersonal conflict among the top managers may have been latent but was not explicit at the outset; during the session, however, as facilitators captured in a diagram participants' experiences and views on the problem, conflict emerged along clear lines of power asymmetry as the CEO offered his own clearly articulated, no-nonsense view of how the group should address the pricing problem. Following the break in the meeting, when participants reconvened, the facilitators directed attention from the CEO and his words back to the shared representation of the aspects of firm and industry interrelationships that reflected their emerging collective understanding of pricing, sales and operations.

This representation, which depicted dependencies among what participants knew from their own experiences, was gradually transformed with the facilitators' help during the subsequent conversation. By directing attention to the shared visual representation, the facilitators de-personalized the conflict because participants could discuss the diagram and suggest changes to it without directly challenging the ranking executive. By soliciting suggestions from all the participants and modifying the diagram to reflect what was said, the facilitators also made the power asymmetry in 
the room, although still present, less relevant. Attention to the visual representation also permitted participants to build on and transform the representation of their integrated understanding. Through this tool, possible policies suggested by participants were represented in modifications to the visual representation, enabling the group to think together about the implications of the dependencies. Because the facilitators wielded the representation as a boundary object, gradual consensus on a policy emerged from the discussion through reasons and hypotheses shared by the group, not because of compliance with the opinion of the highest-ranking participant.

\section{Vignette \#3 Re-interpreted: Inter-agency Social Policy Reform at the County Level}

Conflict-in this case manifested passively as the absence of joint action (Blumer, 1969)—was part of the context in individuals' and agencies' experiences of the persevering problem necessitating cross-agency reforms in a specific area of social policy. During the session, with the facilitators' help, some substantive interrelationships were identified in a shared representation, but the slow process also served to re-entrench participants along agency lines as they expressed primarily their sponsoring organizations' points of view on the complex issue. When the commissioner, the highest-ranking participant, rushed to closure by disregarding the map of interrelated causes and effects, he unilaterally pushed aside the shared visual representation. Why didn't the commissioner's list of eight action items serve as a boundary object? He put forth a new visual representation not generated by participants' conversation and consensus. The commissioner's action item list did not show dependencies among agencies' actions and was not transformable by anyone in the room (including - or maybe especially-by the facilitators). Removing the opportunity for participants to work with a visual representation that could function as a boundary object served to end the conversation in that session so definitively that, in the months following, the conversation was not re-opened by participants.
ANALYSIS: HOW BOUNDARY OBJECTS PROMOTE AGREEMENT IN CONFLICTIVE GROUP MODEL-BUILDING SESSIONS

We view the emergent process of helping participants move toward joint action as multiple stages of building incremental agreements, many of which are represented visually during the collaborative problem-solving process. Representing participants' input visually, identifying dependencies among participants' perspectives and depicting those visually and transforming the accumulating understanding by altering the visual representation place a continually revised "picture" of incremental agreements before participants. Even if participants do not agree with one another's perspectives, they agree that their perspectives are different and yet share some dependencies-that itself comprises a series of agreements. This shared focus, sustained through facilitated discussions creating and modifying visual reminders of a common ground, simultaneously builds participants' trust in one another and in the process generating the emergent agreements. Figure 1 indicates that each stage of a four-stage, facilitated problem-solving process plays a role in reinforcing participants' mutual trust, which in turn enables their greater participation. Critically, the visual representations as boundary objects serve as the group's point of focus and stimulate the activities that create the gradual accumulation of agreements.

We identify four stages of activities, each generating some accumulation of visually represented ideas: (1) Participants generate ideas that accumulate into a stock of salient ideas 'on the table' for the group to consider; (2) Participants identify dependencies among some of the salient ideas and perspectives, creating an accumulation of ideas that also portray consequences of interdependencies among them; (3) Participants transform a portion of the salient ideas by some process of group discussion or idea manipulation to create another stock of tangible and salient ideas modified by their shared input; and (4) Working with these transformed ideas and some process of prioritization, participants create agreements about how the group can move forward. Members' trust in one another and in the 


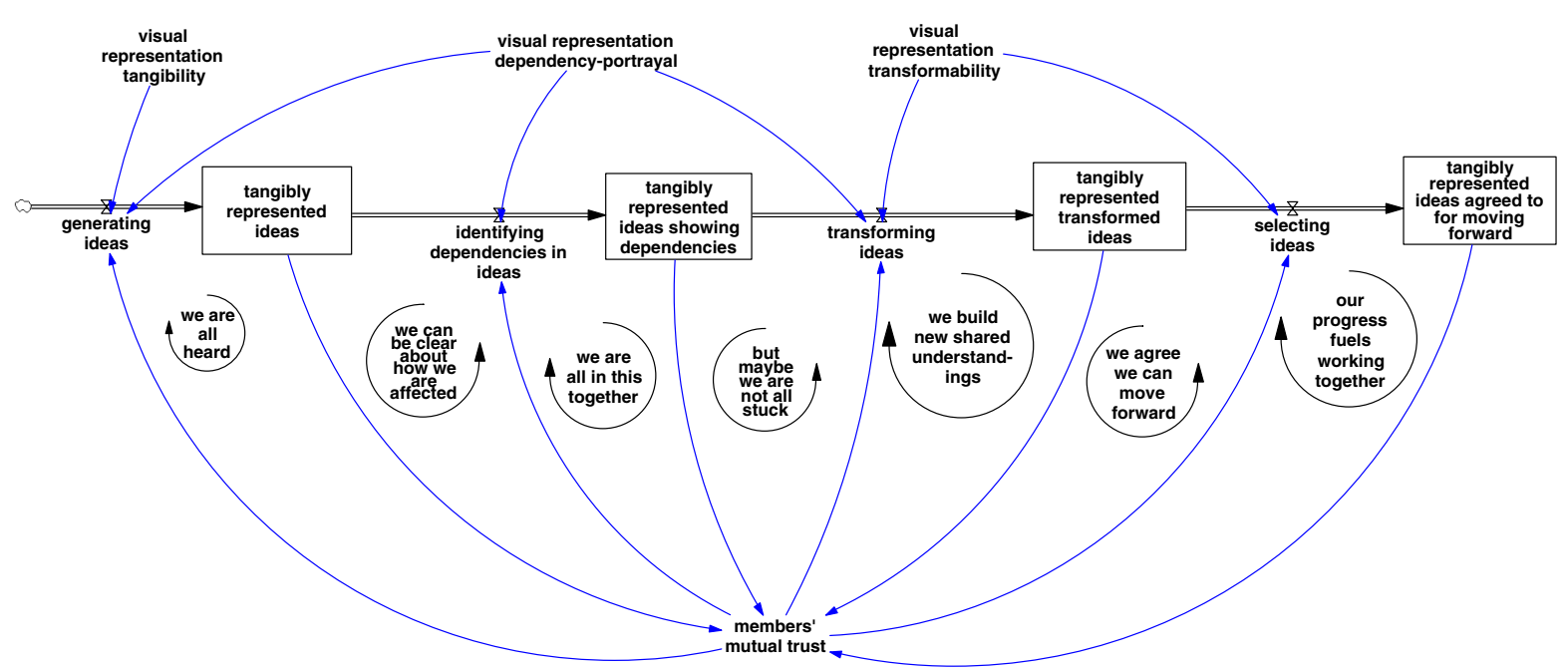

Figure 1 Properties of boundary objects enabling activities that build trust and agreements incrementally

process that advances participants through these stages plays a critical mediating role among activities and accumulations of facilitated script products. The visible script products, wielded as boundary objects, provide early and growing evidence that participants are being heard by facilitators and by one another. This evidence builds trust and at least a limited sense of psychological safety that enables continuing learning behaviors (Carmeli et al., 2009) through the facilitated activities, which in turn creates more evidence that reinforces participants' mutual trust and leads them to participate further in the collaborative problem-solving processes.

In our experiences, we find that structured processes for interaction and facilitation enable the activities that generate and transform ideas, portray them visually and then selectively shape some transformed ideas into paths for joint action. It is straightforward to see that the key attributes of boundary objects-tangibility, representation of dependencies among participants' objectives and resources and transformabilityease the emergent processes. Idea generation is supported by boundary objects that are relatively concrete, given participants' expertise and experience, and able to depict salient dependencies among members of the group. They can 'see what they say' and the consequences of their interdependencies. Because representations are tangible and show salient dependencies, visual representations that function as boundary objects support the ability of the group to transform initial ideas placed 'on the table' into alternatives that retain their salience and tangibility even as they are modified to represent additional dependencies and consequences to participants.

Facilitating collaborative problem solving does not solely depend on visual representations. Clearly, we believe that facilitators' using structured scripts also accelerates the process, and further, we believe that participants must begin with at least a modicum of trust in both the facilitators and the processes they bring. Especially with technology-mediated processes, facilitators draw on a ready source of ways to represent ideas. Facilitators make sure that ideas are represented visually, often unselectively and democratically, because they bear responsibility for the process, not the content. But by ensuring that these representations show dependencies and are modifiable and modified by ongoing participant input (again, often supported by technologies and using structured scripts), they can ensure that the representations serve as boundary objects.

Critically, not every visual representation functions as a boundary object. Let us consider each of the vignettes in light of Figure 1. 
- In the first vignette, participants initially progressed no farther than generating ideas, the first activity in Figure 1, with written words representing their tangible ideas. Because originally their written ideas for improving public safety were observed to be connected with the participants' themselves, all were reluctant to identify dependencies among the ideas because that could imply there were dependencies-perhaps in contradiction to conventional lines of community conflictsamong themselves as well. When the facilitators introduced anonymity into the process of generating ideas, then the visually represented ideas could function as boundary objects because participants then trusted the process sufficiently to identify dependencies among the ideas, building the second stock in Figure 1.

- In the second vignette, the executives and operations managers were progressing through stages of problem solving. They built accumulations of tangibly represented ideas with portrayed interdependencies related to pricing pressures and transformed them with facilitated help. When the CEO expressed his nononsense opinion about how to move forward, he effectively voiced his desire to 'jump stages' directly to the last accumulation of agreements in Figure 1, rupturing the process of gradually building agreements through transformed visual representations. After the session break, the facilitators deliberately returned participants' focus to the visual representation that served as the most recent picture of their agreements thus far. By allowing the discussion to focus on transforming that representation of their ideas, participants-including the CEOreturned to the process of gradually building agreements and eventually arrived together at agreements on how to move forward.

- In the third vignette, agency representatives were slowly building accumulations of tangibly represented ideas, portraying some dependencies and encountering some difficulties in transforming them, as they returned to voicing their sponsoring agencies' views rather than thinking about the image of interdependencies in the context of the problem before them. When the commissioner took the pen from the facilitator's hand and began writing an action-item list before the participants, he not only ruptured the process of building gradual agreements, he also expressed disregard for the process itself and proposed his own view of how to move forward. His action list was a visual representation, but it did not function as a boundary object in any respect. Rather, his un-transformable representation was an expression of power, with which he hoped to persuade or coerce participants to his view of appropriate action.

When faced with a room full of people at the beginning of a structured problem-solving session, facilitators must move quickly to build visual representations of small, incremental agreements because the modicum of trust initially extended to facilitators and their process will be extended for a limited time. They therefore recognize the need to build participants' trust concomitant with the accumulations of tangibly represented ideas and interdependencies-and especially so in situations of conflict. With representations that function as boundary objects, this is possible. Richardson and Andersen (2010) reported using a form of computer-supported boundary object to create an issue map with more than 100 salient and linked concepts in less than $40 \mathrm{~min}$. Howick et al. (2006) reported that a facilitated group of collaborating managers was able to start recombining and transforming ideas in less than $2 \mathrm{~h}$.

The ability to rapidly fill a stock of participantlegitimated, transformed ideas using boundary objects and scripted group model-building techniques has two additional downstream impacts on future agreements. First, in the absence of initial trust among group members, the rapid accumulation of tangible, transformed ideas, representing legitimate compromises or new ideas, can help build trust among participants. They see that the process has the potential to surface alternatives or compromises that could benefit their position, and they may work with opponents to reach a possible beneficial solution from their own point of view. Second, if the formal leadership of the group, that is, the ranking manager or officer participating, is open to letting this process work, then participants' experiencing 
early agreements can rapidly build confidence not only in the facilitators and in the process but also in the leader-participant and in her or his ability and willingness to support compromise agreements. McCartt and Rohrbaugh (1989) have identified managerial openness as a key predictor of success in a large-scale retrospective study of facilitated face-to-face computer-supported meetings generally. We propose that for groups in conflict this managerial openness is especially important. We saw in vignettes 2 and 3 that the leadership's ability to support the facilitated, structured process became a key factor affecting the success or failure in conflict-mired groups.

Our high-level view of how boundary objects promote agreement in conflictive groups is this: Boundary objects' tangibility and dependency representation, coupled with free expression and sometimes an intervening variable of anonymity, promote a rapid ability to get salient ideas 'on the table'. Just doing this builds some trust early, as members of a low-trust group see their own and others' ideas rapidly laid out in a legitimate and transparent fashion. Facilitators' transforming representations from participant input, especially when skilfully used with scripted processes, almost always assures that a few compromises or new ideas can emerge. If the ranking leader-participant demonstrates openness, then both trust among members and trust in the facilitated process can grow rapidly. With these conditions in place, the stock of transformed ideas can grow even further, creating opportunities for identifying agreements on how to move forward. If this process goes well-and for reasons as demonstrated in the vignettes, it might not-the reinforcing processes described in Figure 1 dominate in favourable ways. First, a flow of agreeing behaviors leads to a stock of agreements, which increases members' mutual trust, thereby enabling a larger flow of agreeing behaviors. Similarly, the same initial flow of agreeing behaviors leading to accumulating agreements can further increase the dynamic ability of an open leader-participant to broker further agreeing behaviors.

These reinforcing loops do not always operate in a benign fashion, however. They can also serve to trap a conflictive group in failure. Imagine that for some reason an external event in the room causes members' trust to decrease-some offhand remark or reaction to an external event such as a news broadcast. Then this decrease in trust makes it harder to evoke agreeing behaviors, leading to a lack of accumulating agreements, making it even harder to build future trust, or worse yet, leading to an actual erosion of trust. A similar vicious cycle working in the 'wrong' direction can occur with an initial drop in trust that the ranking leader-participant is open to ideas, perhaps a sour opening remark or off-hand quip, and lead to a similar trap due to participants' perceiving that they cannot effectively transform others' ideas. Furthermore, whether growing momentum of agreeing behaviors leads to substantive, potentially innovative solutions or deteriorates into group-think rests largely on both the scripted processes for systematically probing a problem space and on the facilitators' abilities to ensure that salient representations depict dependencies, the consequences of those dependencies and all participants' ongoing candid input.

\section{CONCLUSIONS AND IMPLICATIONS}

In this paper, we have argued that the presence of well-functioning boundary objects can and does drive conflict resolution in collaborative group model-building projects. Recognizing and knowing how to use boundary objects wisely is a key skill for resolving conflict in groups of participants who are working on a shared problem or issue. Although the notion of boundary objects has been evoked as an organizing frame for group model building (Zagonel, 2002), this paper focuses specifically on the theory of boundary objects as induced and formalized in sociological studies, which refers specifically to transformable visual representations. This paper contributes to research on collaborative problem solving by demonstrating how the formal theory of boundary objects offers a deeper, richer understanding of successes and shortcomings of visual representations as conflict-resolution tools in modelbuilding approaches. The benefits of developing a theoretical understanding of our practices lie 
in helping us recognize the salient elements in many varied complex situations that can serve as points of leverage to accomplish desired outcomes - in this case, making sure visual representations are used as transformable boundary objects to create and sustain collaborative discussion.

We first presented three vignettes illustrating both how conflict can arise and be resolved in group model-building sessions. After presenting three key characteristics of structured group model building as well as three additional characteristics of boundary objects, we used these ideal-type characterizations to re-interpret the dynamics of conflict generation and resolution in the three vignettes. We concluded by presenting a four-stage conceptual model of how technology-supported, facilitated problem-solving sessions create tangibly represented agreements for moving forward. Group members must first be able to tangibly represent ideas from their own perspective. Represented ideas must be depicted in ways that identify dependencies, and these dependencies can often depict conflict among members of the group. Critically, all members of the group must be able to transform the ideas that are under consideration. Only then can concretely represented and transformed ideas be converted into agreements for moving forward.

We conclude with three broad 'take-away' messages to inform collaborative problem-solving practices:

1. Make sure that visual representations are actually boundary objects. Not all good visualizations are good boundary objects. As we saw in the third vignette, the creation of a listing of 'tasks to do', often an artefact used to galvanize alignment around collective next steps, can become a polarizing bludgeon when not used properly. Boundary objects are artefacts whose key properties are activated by the social processes defining how they are used. Good artefacts manipulated with bad social processes do not make boundary objects.

2. Use boundary objects to support idea generation and transformation, especially to map dependencies. The attributes of well-functioning boundary objects make them ideally suited to help groups of individuals in conflict to represent visually their (often conflicting) ideas and to transform unaligned or conflicting initial ideas into ideas that depict points of overlap, interdependencies and often hidden or emerging win-win action points. As we have seen in all three vignettes, when used in scripted settings by neutral facilitators who both have the trust of the group and the ability to separate process from substance, boundary objects can almost always assure that conflicting ideas are placed on the table and points of conflicting interdependencies explicitly mapped. That is, boundary objects can almost always constructively depict, if not resolve, conflicts when used properly.

3. Use boundary objects to create reinforcing trust cycles. Getting to 'yes' or getting groups in conflict to agree almost always involves the rapid creation of some sort of intangible stock of trust or goodwill, if only a calculated form of trust that lasts for the duration of the meeting. We believe these stocks of trust accrue as members in conflict work together to create and transform visual representations of their collective ideas. The very act of co-creating a visual representation of conflicting ideas, when accomplished as a joint activity by participants, can build mutual respect and trust. Vignette 1 illustrated how an anonymous, face-to-face and computer-supported brainstorming process can touch off three reinforcing processes that we labelled 'We are all heard', 'We can be clear about how we are affected' and 'We are all in this together'. Rapidly built stocks of trust and mutual respect are essential to reaching common agreement by the end of the group's facilitated process. As discussed in all three vignettes, leadership openness is a key intervening variable that has been demonstrated to drive a group's ability to agree.

In sum, visual representations must be created and transformed with processes that produce the three powerful effects of boundary objects: (1) representations tangible to participants, given 
their different experiences, (2) an ability to portray dependencies among participants' resources and goals and (3) transformability. Boundary objects can and do drive conflict resolution in collaborative model-building meetings when combined with the following: (A) process and content separation, (B) a contract of trust between facilitator and participants and (C) explicit, scripted sub-processes that focus on visual products and deliverables.

\section{ACKNOWLEDGEMENTS}

The authors would like to thank the editors and three anonymous reviewers for helpful suggestions and comments.

\section{REFERENCES}

Ackermann F, Andersen DF, Eden C, Richardson GP. 2011. ScriptsMap: a tool for designing multi-method policy-making workshops. Omega 39(4): 427-434.

Ackermann F, Eden C. 2001. Contrasting single user and networked group decision support systems for strategy making. Group Decision and Negotiation 10(1): 47-66.

Ackermann F, Eden C, Brown I. 2005. The Practice of Making Strategy. Sage: London.

Ackoff RL. 1979. The future of operational research is past. The Journal of the Operational Research Society 30(2): 93-104.

Andersen DF, Richardson GP. 1997. Scripts for group model building. System Dynamics Review 13(2): 107-129.

Andersen DF, Richardson GP, Vennix JAM. 1997. Group model building: adding more science to the craft. System Dynamics Review 13(2): 187-201.

Argyris C. 1993. Knowledge for Action. A Guide to Overcoming Barriers to Organizational Change. JosseyBass Wiley: San Francisco.

Blumer H. 1969. Symbolic Interactionism: Perspective and Method. University of California Press: Berkeley, CA.

Carlile PR. 2002. A Pragmatic View of Knowledge and Boundaries: Boundary Objects in New Product Development. Organization Science 13(4): 442-455.

Carmeli A, Brueller D, Dutton JE. 2009. Learning behaviors in the workplace: the role of high-quality interpersonal relationships and psychological safety. Systems Research and Behavioral Science 26(1): 81-98.

Eden C, Ackermann F. 1998. Making Strategy: The Journey of Strategic Management. Sage: London.
Eden C, Ackermann F, Bryson J, Richardson GP, Andersen DF, Finn C. 2009. Integrating modes of policy analysis and strategic management practice: requisite elements and dilemmas. Journal of the Operational Research Society 60(1): 2-13.

Eden C, Huxham C. 2006. Researching organizations using action research. In Handbook of Organization Studies, Nord W (ed.). Sage: Beverly Hills; 388-408.

Eisenhardt KM. 1989. Building theories from case study research. Academy of Management Review 14(4): 532-550.

Henderson K. 1991. Flexible sketches and inflexible data bases: visual communication, conscription devices, and boundary objects in design engineering. Science, Technology, E Human Values 16(4): 448-473.

Henderson K. 1998. The role of material objects in the design process: a comparison of two design cultures and how they contend with automation. Science, Technology, E Human Values 23(2): 139-174.

Hovmand PS, Rouwette EAJA, Andersen DF, et al. 2011. Scriptapedia 3.04. http: / /www.systemdynamics.org/ conferences/2011/proceed/papers/P1404.pdf [21 July 2011].

Howick S, Ackermann F, Andersen DF. 2006. Linking event thinking with structural thinking: methods to improve client value in projects. System Dynamics Review 22(2): 113-140.

Kim H. 2009. In search of a mental model-like concept for group-level modeling. System Dynamics Review 25(3): 207-223.

Lave J. 1988. Cognition in practice: mind, mathematics, and culture in everyday life. Cambridge University Press: Cambridge, New York.

McCartt AT, Rohrbaugh JW. 1989. Evaluating group decision support system effectiveness: a performance study of decision conferencing. Decision Support Systems 5(2): 11.

McKenzie J, Winkelen CV. 2011. Beyond words: visual metaphors that can demonstrate comprehension of KM as a paradoxical activity system. Systems Research and Behavioral Science 28(2): 138-149.

Randers J. 1980. Guidelines for model conceptualization. In Elements of the System Dynamics Method, Randers J (ed.). Productivity Press: Cambridge, MA; 117-139.

Richardson G, Andersen DF. 1995. Teamwork in group model building. System Dynamics Review 11(2): 113-137.

Richardson GP. 2006. Concept models. Paper presented at the International Conference of the System Dynamics Society, Nijmegen, The Netherlands.

Richardson GP, Andersen DF. 2010. Systems thinking, mapping, and modeling in group decision and negotiation. In Handbook of Group Decision and Negotiation, vol. 4, Kilgour DM, Eden C (eds.). Springer: Dordrecht; 313-324.

Rittel HWJ, Webber MM. 1973. Dilemmas in a general theory of planning. Policy Sciences 4(2): 155-169.

Schein EH. 1969. Process Consultation: Its Role in Organization Development. Addison-Wesley Publishing Company: Reading, MA. 
Star SL, Griesemer JR. 1989. Institutional ecology, 'translations' and boundary objects: amateurs and professionals in Berkeley's Museum of Vertebrate Zoology, 1907-39. Social Studies of Science 19(3): 387-420.

Vennix JAM. 1996. Group Model Building: Facilitating Team Learning Using System Dynamics. John Wiley \& Sons: New York.

Vennix JAM. 1999. Group model-building: tackling messy problems. System Dynamics Review 15(4): 379-401.

Vennix JAM, Akkermans HA, Rouwette E. 1996. Group model-building to facilitate organizational change: an exploratory study. System Dynamics Review 12(1): 39-58.

Wolstenholme E. 1994. A systematic approach to model creation. In Modeling for Learning Organizations, Morecroft JDW, Sterman JD (ed.). Productivity Press: Portland, OR.

Zagonel AA. 2002. Model conceptualization in group model building: a review of the literature exploring the tension between representing reality and negotiating a social order. Palermo, Italy (July 28-August 1). Winner of the 2002 Dana Meadows Award. 